\title{
RELIGIÃO, MERCADO RELIGIOSO E PROTESTO POLÍTICO NA AMÉRICA LATINA
}

\author{
Alice Vila Nova Procopiuk Walter ${ }^{1}$ \\ Ednaldo Aparecido Ribeiro ${ }^{2}$
}

\begin{abstract}
Resumo
A literatura sobre as relações entre religião e política na América Latina tem sugerido que mercados religiosos mais fechados geram maior ativismo entre grupos denominacionais minoritários. Essas análises, porém, se concentram na atuação de elites políticas e atores coletivos, sendo raros os testes envolvendo o comportamento do cidadão médio. Diante disto, o presente artigo investiga os efeitos do fenômeno religioso na sua dimensão individual e contextual sobre o protesto político nessa região. Combinando dados produzidos pelo Latin American Public Opinion Project com medidas do Pew Research Center e da Association of Religion Data Archives, foram propostos modelos de regressão logísticos hierárquicos. Os resultados indicam efeitos reduzidos da afiliação religiosa e impactos mais consistentes da frequência aos cultos/missas. Os efeitos do contexto religioso reforçam essa conclusão, já que a maioria dos indicadores não se mostrou relevante na explicação da participação em protesto.
\end{abstract}

Palavras-Chave: Protesto; Ativismo Religioso; Contexto Religioso; América Latina.

\section{INTRODUÇÃO}

A literatura norte-americana e europeia sobre participação política consolidou a relevância do ativismo religioso e da afiliação denominacional sobre o comportamento político individual (VERBA, SCHLOZMAN e BRADY, 1995; PUTMAN, 2000; DJUPE e GRANT, 2001; JONESCORREA e LEAL; 2001; CAMPBELL, 2004). Na América Latina, diferentemente, as análises acerca da relação entre religião e política têm enfatizado a importância do contexto religioso, investigando como indivíduos e atores coletivos interagem ou reagem a situações impostas por este entorno.

É o que percebemos, por exemplo, nos trabalhos de Helmsdorff (1996), Bastian (1999), Maróstica (2000) e Wynarczkyk (2007), que enfatizam a luta evangélica, enquanto minoria no mercado religioso regional, pelo fim de um favoritismo católico legal e estatal, em prol da luta pela

1 Doutora em Ciência Política pela Ufpr, alice14@gmail.com, ORCID: https://orcid.org/0000-0001-9423-7110

2 Doutor em Sociologia pela Ufpr - PR, Brasil; professor associado de Ciência Política na UEM - PR, Brasil e docente permanente do Programa de Pós-graduação e Ciência Política da Ufpr, earibeiro@uem.br, ORCID: https://orcid.org/0000-0002-4005-5108 
igualdade perante a lei, pela liberdade religiosa. A pesquisa de Boas (2018), dá um passo adiante na análise sobre a importância do contexto religioso para ação política dos fiéis, destacando o papel da percepção de ameaça aos direitos e liberdades como motivação para o engajamento político entre grupos religiosos. Interessado em entender as diferenças na atuação política eleitoral de evangélicos no Brasil e no Chile, o autor descreve como no primeiro o catolicismo conseguiu recuperar seus privilégios perdidos ou limitados com o estabelecimento da República, enquanto no outro país estes privilégios legais foram significativamente reduzidos, acarretando um menor incentivo à ação política. Enquanto no Brasil a separação constitucional da Igreja e do Estado foi constantemente contestada pelo catolicismo, no Chile não se procurou recuperar, de forma efetiva, os privilégios perdidos, fazendo com que evangélicos não se sentissem ameaçados. Entre os brasileiros a recuperação dos privilégios legais católicos foi encarada como uma injustiça, que serviu de motivação para a luta pelo fim de tal favorecimento, acarretando mobilização política eleitoral. A atuação menos ativa dos evangélicos chilenos seria, portanto, efeito da reduzida percepção de ameaça dessa minoria religiosa (BOAS, 2018).

Smith (2018) também contribui para a reflexão acerca dos efeitos da percepção de injustiça ou de favoritismo por parte da regulamentação estatal no contexto brasileiro. Tratando das posições políticas adotas pelo clero frente a competição estratégica entre congregações católicas e evangélicas, a autora afirma que o trânsito religioso e a mudança no cenário ocorridos nas últimas décadas teriam forçado os grupos religiosos a competirem por almas e recursos financeiros (SMITH, 2018). As estratégias de concorrência, contudo, dependeriam da extensão da regulamentação (ou do secularismo) estatal sobre os grupos religiosos. Assim, para Smith, a extensão desta regulação está relacionada com a forma como os líderes se comportam frente a política, fazendo com que quanto mais secular ou mais próximo de um fim secular um Estado estiver, mais seus líderes se concentram nos fiéis e na competição direta com outros grupos. Em oposição, quanto menos secular um país, mais os líderes religiosos veriam a necessidade de concentrar seus esforços no próprio Estado, a fim de não se sentirem prejudicados ou menos favorecidos.

Desta forma, a extensão do secularismo afetaria a preocupação política do clero, fazendo com que estes ou se dediquem mais a concorrência religiosa ou lutem contra políticas que considerem prejudiciais ao seu grupo. Essa percepção acerca do tratamento estatal dispensado às denominações, de acordo com Smith (2018), interfere na forma como o clero conversa com seus fiéis sobre o ativismo político (IBIDEM). 
Tais trabalhos, sugerem, portanto, que a ação política de determinados grupos foi desencadeada como uma possível resposta a uma provocação vinda de seu contexto religioso nacional desigual. Ao se sentirem ameaçados nos seus direitos, estes religiosos teriam decido sair de sua posição de conforto, engajando-se em uma ação por meio da qual conseguissem lutar ou manifestar seus interesses. Esse olhar sobre os contextos religiosos não é frequente na agenda de pesquisas sobre comportamento político, que tende a enfatizar a relevância das instituições religiosas sobre os níveis de engajamento político de seus fiéis sem considerar a posição relativa das diferentes denominações dentro dos mercados religiosos nacionais.

Verba, Schlozman e Brady (1995) e Putman (2000), por exemplo, destacam o papel das igrejas no desenvolvimento de habilidades cívicas e no estabelecimento de redes de contato que permitem mobilização e recrutamento necessários à participação política. A desconsideração desse contexto mais amplo, ainda que não desvalorize os achados dessas pesquisas, não colabora para o desvendamento do processo de conversão dessas habilidades e redes de contato em uma ação política orientada para determinados fins específicos. Djupe e Grant (2001) criticam essa limitação e tentam preencher tal lacuna defendendo que, apesar das habilidades desenvolvidas na igreja fomentarem a ação política, tal processo não se daria de forma automática, sendo necessário um esforço consciente e intencional de ação. Jones-Correa e Leal (2001) e Campbell (2004) contribuem para o desenvolvimento desse argumento ao apontarem para a capacidade mobilizadora da igreja em determinados momentos, por meio de contatos sociais utilizados de forma esporádica, sob condições desencadeadoras ou de ameaça, reagindo a questões e assuntos específicos.

A crítica levantada por Djupe e Grant (2001) aponta a necessidade de considerarmos a existência de um possível fator desencadeador da ação política, um fator de ameaça comum entre estes religiosos, que poderia servir como um gatilho para o engajamento, derivado do contexto. Considerando esse argumento válido, nesse artigo nossa intenção é analisar como os condicionantes individuais documentados pela literatura comportamentalista (basicamente recursos, envolvimento cognitivo e recrutamento) interagem com essa dimensão contextual (HOX, 2010). Mais especificamente nos interessa responder as seguintes questões: limitações impostas pelo mercado religioso, via regulamentações estatais ou preconceito social, impulsionam o ativismo de protesto de minorias religiosas? Como esses contextos desfavoráveis impactam a forma como características individuais influenciam a ação política?

Ainda que os trabalhos citados apontem para a relevância desses cenários, no contexto latino-americano, marcado por profundas desigualdades na distribuição dos recursos necessários ao 
engajamento cívico do cidadão médio, suspeitamos que o descontentamento com medidas restritivas ou em relação ao preconceito religioso não sejam motores relevantes do ativismo político, principalmente de protesto. Apesar do agravo, nos termos definidos por Gurr (1971), aparecer frequentemente como fator relevante nas discussões sobre as causas da participação política, principalmente nos estudos clássicos sobre movimentos sociais (GURR, 1971; MCADAM, 1999), de acordo com Dalton, Van Sickle e Weldon (2009) são poucas as evidências empíricas que sustentam o seu efeito sobre o engajamento individual. Nossa hipótese, portanto, é que entre os países latino-americanos a maior ou menor abertura do mercado religioso à grupos minoritários não afeta a probabilidade de ativismo político do cidadão médio.

Essa hipótese, todavia, não implica na negação da relevância da religião para a explicação do comportamento individual, pois trabalhamos também com a hipótese complementar de que o ativismo religioso, medido pela frequência à cultos/missas, teria um efeito positivo sobre o envolvimento em ações de protesto. Nossa expectativa é que a filiação religiosa específica dos entrevistados não afeta a sua probabilidade de atuação, mas a intensidade do seu envolvimento com a instituição sim, já que segundo o já clássico Voice and Equality (1995), a frequência nas atividades promovidas pelas igrejas pode favorecer o desenvolvimento das habilidades necessárias ao ativismo político. Segundo a tese do Voluntarismo Cívico de Verba, Schlozman e Brady (1995, 2012), as igrejas ou instituições religiosas funcionam como um local de desenvolvimento de habilidades cívicas, organizacionais e comunicacionais e como canais de mobilização e recrutamento, contribuindo, assim, para o envolvimento dos indivíduos nas atividades políticas. Tais instituições religiosas teriam, então, o potencial de reforçar os recursos políticos disponíveis aos cidadãos que, de outra forma, não teriam oportunidades de desenvolver suas habilidades, funcionando não apenas como organizações espirituais e sociais, mas também como geradoras de envolvimento político. Esse efeito, todavia, não seria modulado pela condição de minoria religiosa ou pelo contexto do mercado religioso marcado por desigualdades ou privilégios.

\section{DADOS E SELEÇÃO DE VARIÁVEIS}

A identificação dos efeitos de aspectos contextuais ligados aos mercados religiosos nacionais e a sua interação com características individuais, como denominação e intensidade do ativismo religioso, impõe o uso de dados de diferentes níveis. Em razão dessa estrutura 
hierarquizada das informações, com indivíduos agrupados em países, o modelo estatístico empregado no trabalho procura determinar o efeito direto de variáveis explicativas de cada um desses níveis, mas também as eventuais moderações provocadas pelos preditores macro (nacionais) sobre os efeitos dos determinantes individuais (HOX, 2010; SOMMET e MORSELLI, 2017).

O material empírico de nível individual é fornecido pelo Latin American Public Opinion Project - American Barometer (Lapop), mais especificamente por suas rodadas de 2012 e 2016/17. Dentre as diversas modalidades de participação política incluídas nessas sondagens, selecionamos para ocupar a posição de variável dependente o envolvimento em manifestações e protestos públicos. Essa medida é derivada da seguinte pergunta: Nos últimos doze meses, o(a) sr./sra., participou de alguma manifestação ou protesto público? Trata-se, portanto, de uma medida dicotômica em que o "sim" é codificado como 1 .

Segundo Dalton, Van Sickle e Weldon (2009, p. 1) o protesto tornou-se um mecanismo de influência pública sobre a formulação e a implementação de políticas governamentais e tem aumentado em nível global, tornando-se "uma parte onipresente da política contemporânea". Considerando a regulamentação estatal da religião apresentada na seção anterior e a luta pela liberdade e igualdade religiosa por parte de alguns grupos, vemos como importante entender a relação dos ativistas religiosos com essa modalidade de ação. Isso se torna ainda mais relevante quando levamos em conta as pesquisas de Moseley (2015) e Smith (2018).

Moseley, assim como Dalton, Van Sickle e Weldon (2009), vai destacar o crescimento desta forma de ação política, porém, dando destaque à América Latina. Buscando estudar a interação entre o contexto institucional e os padrões de envolvimento da comunidade com relação à propensão dos indivíduos a se engajarem em táticas contenciosas, o autor vai destacar a importância do envolvimento em comunidades cívicas, na tentativa de explicar o que chama de "explosão da participação em protesto em grande parte da América Latina" (MOSELEY, 2015, p.3).

Ainda nesse nível individual, as duas variáveis independentes fundamentais na nossa pesquisa são 1) denominação religiosa dos respondentes, já que possibilita a identificação de probabilidades distintas de engajamento em protesto de membros de grupos minoritários e majoritários em termos do espaço ocupado no mercado religioso e 2) ativismo religioso, medido pela assiduidade, para identificar os efeitos da intensidade do envolvimento sobre o engajamento político por meio do desenvolvimento de habilidades cívicas (VERBA, SCHLOZMAN e BRADY, 1995; 2012). A primeira é originalmente mensurada pela frequência à missas ou cultos com as alternativas "mais de uma vez por semana", “uma vez por semana", "uma vez por mês", "uma ou 
duas vezes por ano" e "nunca ou quase nunca", mas foi recodificada como binária reunindo na categoria "ativos" aqueles que participam com uma frequência igual ou superior a "uma vez por mês". A segunda variável, que originalmente comportava mais de 10 alternativas, foi reduzida para as seguintes categorias: "católico", evangélico", "outras religiões" e "sem religião".

No nível macro estabelecemos quatro variáveis que retratam a regulamentação estatal da religião. Assim como Fox (2015), entendemos como limitadas as abordagens que distinguem países pela existência ou não de uma "religião oficial". Consideramos essa separação dicotômica simplista e incapaz de conter a complexa realidade, já que não consegue identificar em que medida o Estado apoia determinada religião, a extensão de seu controle, regulamentação e restrição. Por essa razão, utilizamos nesse trabalho a medida de "Suporte Oficial do Estado", proposta pela Association of Religion Data Archives (ARDA). A relação formal entre religião e Estado é categorizada de 14 formas diferentes nesse constructo. Nas categorias de 0 a 9 são enquadrados países sem religião oficial, sendo esses diferenciados internamente em razão da intensidade do apoio que dispensam a uma única denominação específica. As demais codificações, de 10 a 13, dizem respeito aos Estados com religiões oficiais, sendo também ordenados internamente em razão do menor ou maior apoio estatal à religião. Em nossos modelos optamos por incluir essa medida como uma variável numérica, já que o ordenamento das categorias é bastante claro. Detalhes sobre cada uma dessas categorias podem ser consultadas no Anexo.

A segunda variável diz respeito à obrigatoriedade da educação religiosa nas escolas públicas, denominada "Educação Requerida", também disponibilizada pelo ARDA. Segundo Kuru (2009), os debates históricos e contemporâneos sobre a relação entre religião e Estado apontam para a relevância de se trazer a educação para a discussão. Fox (2015) afirma também a relevância desse tema, principalmente em razão do grande número de crianças educadas em escolas públicas, financiadas e administradas pelo Estado (FOX, 2015).

Ainda com relação ao padrão de interações entre Estados e religião, recorremos ao Pew Research Center para incluir o "Índice de Restrição de Governo" (GRI), que mede não apenas as leis, mas também as políticas e ações governamentais que restringem crenças ou práticas religiosas. Esse índice compreende 20 medidas sobre restrições, banimentos, proibições, limitações e favorecimentos, todas mensuradas em escala de 0 a 10 pontos. Após procedimento somatório o índice também foi ajustado para variar de 0 a 10.

Além das restrições governamentais, a violência e a intimidação nas sociedades também podem limitar as crenças e práticas religiosas, sendo assim, a segunda medida extraída do Pew foi o 
"Índice de Hostilidades Socais" (SHI), cuja função é medir os atos de hostilidade religiosa praticados por particulares, organizações ou grupos sociais. Essa medida agrega 13 itens relacionados à hostilidade, dentre elas conflitos armados relacionados à religião, violência popular, assédio ou outras intimidações ou abusos com base religiosa. Esses itens foram somados e a medida final padronizada para a escala de 0 a 10 (Anexo).

Apesar de nosso interesse recair predominantemente sobre o papel do ativismo e do contexto religioso na participação em protestos entre os latino-americanos, não podemos deixar de fora variáveis políticas e econômicas preditoras já consolidadas pela literatura politológica, que funcionam aqui como medidas de controle tanto no nível micro quanto macro. No que se refere ao contexto político amplo, Dalton, Van Sickle e Weldon (2009) e Ribeiro e Borba (2015) apontam diversos estudos que, partindo das teorias das Estruturas de Oportunidade Política, tratam da influência de arranjos institucionais e processos políticos sobre a participação política, incentivando diferentes formas de engajamento e afetando suas expectativas de sucesso ou fracasso (TARROW, 1997; KITSCHELT, 1986; EISINGER, 1973). Segundo esta linha teórica, as condições dos protestos dependem, principalmente, das configurações das oportunidades de ação coletiva, seguida por elementos institucionais e estruturais mais estáveis, como a força/fraqueza e abertura/fechamento do Estado, seus incentivos e restrições (TARROW, 1997).

Considerando esses argumentos, acrescentamos em nossos modelos a medida Varieties of Democracy (V-Dem), como proxy para a abertura política dos países da região. Tal índice é desenvolvido com base na definição de Dahl de poliarquia e conta com indicadores de liberdade de associação, eleições limpas, liberdade de expressão, idoneidade dos processos eleitorais e a extensão de direitos políticos. Esta medida, bem como os demais indicadores sócio-políticos foram padronizados em uma escala de 10 pontos.

Já no que se refere às condições econômica, a discussão gira em torno das teorias do Agravo e da Mobilização de Recursos. De acordo com a primeira, é a insatisfação popular, causada pela pobreza, a privação econômica, as mudanças na economia nacional, e condições negativas que estimulam a participação em protestos. A teoria dos recursos, segue outro caminho de argumentação, sugerindo que para que a ação de protesto ocorra é necessário que haja uma base de recursos, como estruturas de comunicação densas, educação e urbanização, que facilite a mobilização dos grupos. Essa teoria defende que quanto maior o desenvolvimento econômico, maior a produção de recursos, o que facilitaria a ação política (cf. DALTON, VAN SICKLE e WELDON, 2009; RIBEIRO e BORBA, 2015). 
A despeito desta divergência, consideramos importante controlar os efeitos de nossos candidatos a preditores relevantes por informações sobre a situação econômica latino-americana, selecionando primeiramente a Taxa de Desemprego dos países. Neste ponto nos distanciamos de Dalton, Van Sickle e Weldon (2009), que preferem utilizar o Pib per capita. Como apontam Ribeiro e Borba (2015), entre os países latino-americanos taxas de desigualdade econômica ainda persistem, então, medidas sobre crescimento econômico geral, sem levar em conta essa desigualdade, pode render resultados não satisfatórios. A taxa de desemprego nos parece ser um indicador mais ligado ao agravo e recursos em contextos marcados por fortes assimetrias sociais e econômicas.

Para a escolha dos controles de nível individual, voltamos a seguir Dalton, Van Sickle e Weldon (2009), que apontam para três teorias principais sobre os determinantes do protesto: a teoria do agravo, recursos e valores políticos. No que diz respeito à primeira, selecionamos o nível de satisfação com a vida, com a democracia e um índice de confiança institucional.

Já para a teoria dos recursos (VERBA, SCHLOZMAN e BRADY, 1995), selecionamos a escolaridade, em nosso modelo binarizada para distinguir entrevistados com formação superior (superior=1). Além disso, acrescentamos uma variável relativa ao interesse por política, na expectativa de que funcione como proxy para engajamento subjetivo, e uma variável sobre o envolvimento dos indivíduos em organizações e associações - medida aqui pela participação em reuniões de associação de bairro ou juntas de melhorias para a comunidade. Essa última medida cobriria o que os autores de Voice and Equality chamaram de estruturas de recrutamento.

Por fim, temos a teoria dos valores, cuja medida selecionada foi a variável de ideologia política, uma vez que pesquisadores têm vinculado a atividade de protesto a orientações ideológicas amplas. Diferentemente de Dalton, Van Sickle e Weldon (2009), não conseguiremos acrescentar em nosso modelo a variável de adesão aos valores pós-materialistas, uma vez que a base do Lapop por nós utilizada não apresenta as questões que nos permitiriam operacionalizar um índice sobre essas novas prioridades valorativas.

O modelo estatístico adequado para a estrutura desses dados é a modelagem multinível, que possibilita a determinação dos efeitos diretos de variáveis explicativas individuais e em nível de contexto. Além disso, permite avaliar se as variáveis explicativas no nível macro servem como moderadores das relações em nível individual, indicando se há variabilidade do impacto de um preditor de interesse em função de outras variáveis (HOX, 2010).

Esta técnica, portanto, se aplica a estruturas de dados hierárquicos, sendo útil em investigações de problemas que envolvem a relação entre os indivíduos e seus coletivos, 
pressupondo que pessoas interagem e são influenciadas pelos grupos ou contexto sociais dos quais fazem parte (RAUDENBUSH e BRYK, 2002). A análise multinível lida com essa estrutura e torna visíveis os efeitos dentro de determinado grupo (ou cluster) e entre os diferentes grupos (HOX, 2010; SOMMET e MORSELLI, 2017).

Para tanto, os modelos são construídos de forma que a variável resposta esteja no nível mais baixo, isto é, assume-se a existência de um conjunto de dados, com um único resultado ou variável de resposta que é medido no primeiro nível, e que possui variáveis explicativas em todos os níveis. Essa medida dependente, em nosso estudo específico, apresenta uma distribuição binomial, comportando os valores 0 (não) e 1 (sim). Sendo assim, utilizamos modelos de Regressão Logística Multinível, usados quando a intenção é estimar os efeitos de preditores sobre a razão de chance de ocorrência de um evento de interesse (HOSMER, LEMESHOW e STUDIVANT, 2013; SOMMET e MORSELLI, 2017).

\section{RESULTADOS E DISCUSSÃO}

Para avaliar se a modelagem multinível de fato se aplica ao nosso problema de pesquisa, em um primeiro momento estimamos um modelo nulo de dois níveis, que é uma equação com apenas um efeito de intercepção e de grupo que permite estimar as probabilidades de participação em protestos, sem a inclusão de preditores. $\mathrm{O}$ intercepto fixo $\beta_{0}$ é um termo constante geral, e é compartilhado por todos os países incluídos na amostra, enquanto o efeito aleatório $\mu_{o j}$, é específico para o país $j$ (representando cada um dos países específicos), como se pode ver na equação abaixo:

$$
\log \left(\frac{\pi_{i j}}{1-\pi_{i j}}\right)=\beta_{0}+\mu_{o j}
$$

Na Tabela 1 conseguimos ver os principais resultados desse primeiro passo da análise. Observamos que o logaritmo da razão de chance da participação em protestos ou manifestações públicas em um país "médio" é de $-2,46$, valor esse que ao ser exponenciado demonstra uma percentagem de $8 \%$ de participação na região. A variância da razão de chance entre os países é de 0,25 e para saber se essa diferença é estatisticamente significativa conduzimos um teste de razão de probabilidade para afastar a hipótese de que essa variabilidade é igual a 0. Neste procedimento o modelo nulo é comparado com o seu equivalente de nível individual, ou seja, sem os efeitos 
aleatórios dos países, cujo resultado da linha "log-lik" apresentou o valor de $-751,83$, bastante superior ao que indicaria a inexistência de variabilidade.

TABELA 1 - MODELO NULO PARA PARTICIPAÇÃO EM PROTESTOS NA AMÉRICA LATINA

\begin{tabular}{lc}
\hline Log da Razão de chance em um país “médio” & $-2,46$ \\
\hline Variância no log da razão de chance entre os países & 0,25 \\
\hline Log-lik & $-751,83$ \\
\hline AIC FONTE: Elaboração própria com base nos dados do Lapop 2012 e 2016/17
\end{tabular}

No gráfico Caterpillar abaixo, composto pelos resíduos e com barras representando os respectivos intervalos de confiança em torno de cada estimativa, notamos que existe uma variação considerável, uma vez que os efeitos se encontram, em sua maioria, abaixo ou acima do intervalo de confiança. Em um modelo como o aqui utilizado, assume-se que existe um conjunto de dados hierarquizados, com um resultado ou variável resposta que é medido no nível mais baixo, e variáveis explicativas em todos os níveis existentes (HOX, 2010). Assim, após observar a existência desse efeito no nível dos países, procuramos testar os preditores de nível micro, isto é, buscamos identificar os fatores de nível individual ligados à participação em protesto.

\section{GRÁFICO 1 - EFEITO-PAÍS SOBRE A PROBABILIDADE DE ATIVISMO DE PROTESTO NA AMÉRICA LATINA}
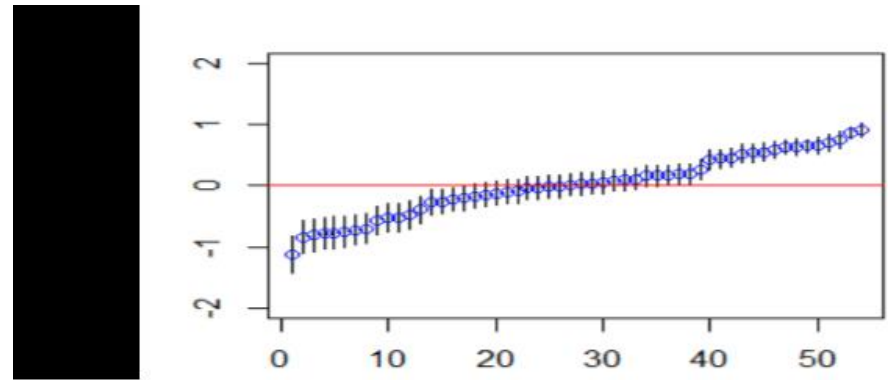

FONTE: Elaboração própria com base nos dados do Lapop, 2012 e 2016/17

Utilizando as variáveis já expostas, construímos um modelo de efeitos fixos contendo apenas medidas preditoras de nível individual, complementado por uma coluna de variância gerada por um modelo alternativo com efeitos variáveis. Esse complemento é importante para identificarmos a variabilidade dos efeitos de cada preditor sobre a probabilidade do ativismo de protesto, pois isso indicará que tipo de interações podem ser testadas em etapa posterior. Variação 
significativa dos efeitos de uma medida entre os países sugere relevância de características nacionais.

Começando pelo ativismo religioso, os resultados demonstram que a condição de ativo (com frequência igual ou superior a uma vez por mês) aumenta em $9 \%$ a probabilidade de um indivíduo se engajar nesta modalidade de ativismo. Este resultado confirma a hipótese de que a frequência a locais de culto aumenta as chances de um indivíduo latino-americano participar de manifestações e protestos públicos, sendo coerente com o defendido por Verba, Schlozman e Brandy (1995). Lembramos que, para esses autores, a assiduidade religiosa contribui para o desenvolvimento de habilidades cívicas, para o recrutamento e mobilização para a ação política.

TABELA 2 - EFEITOS DE PREDITORES INDIVIDUAIS SOBRE PARTICIPAÇÃO EM PROTESTOS NA AMÉRICA LATINA

\begin{tabular}{|c|c|c|c|}
\hline & $\begin{array}{c}\mathbf{B} \\
\text { (erro) } \\
\end{array}$ & $\operatorname{Expo}(B)$ & Variância \\
\hline Católico & $\begin{array}{c}-0,50 * * * \\
(0,061)\end{array}$ & 0,60 & 0,096 \\
\hline Evangélico & $\begin{array}{c}-0,48 * * * \\
(0,072)\end{array}$ & 0,61 & 0,088 \\
\hline Outras Religiões & $\begin{array}{c}-0,50 * * * \\
(0.097)\end{array}$ & 0,60 & 0,025 \\
\hline Ativismo Religioso & $\begin{array}{c}0,09 * \\
(0,041)\end{array}$ & 1,09 & 0,005 \\
\hline Associação & $\begin{array}{c}0,41 * * * \\
(0,018)\end{array}$ & 1,51 & 0,008 \\
\hline Escolaridade & $\begin{array}{c}0,48 * * * \\
(0,040)\end{array}$ & 1,61 & 0,046 \\
\hline Interesse & $\begin{array}{c}0,47 * * * \\
(0,018)\end{array}$ & 1,60 & 0,000 \\
\hline Satisfação Democracia & $\begin{array}{c}-0,01 \\
(0,026)\end{array}$ & 0,98 & 0,004 \\
\hline Satisfação Vida & $\begin{array}{c}-0,11 * * * \\
(0,023)\end{array}$ & 0,88 & 0,004 \\
\hline Confiança & $\begin{array}{c}-0,68 * * * \\
(0,085)\end{array}$ & 0,50 & 0,329 \\
\hline Ideologia & $\begin{array}{c}-0,04 * * * \\
(0,006)\end{array}$ & 0,95 & 0,003 \\
\hline AIC & \multicolumn{2}{|c|}{21652,8} & \\
\hline Variância & \multicolumn{2}{|c|}{0,2186} & \\
\hline
\end{tabular}

FONTE: Elaboração própria com base nos dados do Lapop, 2012 e 2016/17 
Se nesse sentido nossos dados se aproximam dos destes autores, no que se refere ao papel das denominações ou afiliações religiosas eles se distanciam, corroborando o que foi defendido por Jones-Correa e Leal (2001), Lockerbie (2013) e Gerber, Gruber e Hungerman (2015), para os quais a importância da instituição religiosa está em seu papel enquanto uma associação civil, uma vez que o envolvimento dos indivíduos seria mais relevante do que a diferença denominacional. Isso porque, em nosso modelo, em relação a categoria “sem religião', ser católico diminui em $40 \%$ as chances de um indivíduo se engajar em protestos. O mesmo ocorre com as demais denominações aqui abordadas, diminuindo entre os evangélicos $39 \%$ e entre outras religiões $40 \%$.

É importante destacar que todas as religiões se comportam de maneira semelhante, reduzindo em bloco o ativismo de protesto, sugerindo que a condição de minoria ou maioria religiosa não impacta a probabilidade de protestar. Esse resultado sugere que a hipótese do efeito do grau de abertura do mercado religioso não se verifica na região latino-americana, já que a sua confirmação passaria pela identificação de efeitos positivos de denominações evangélicas ou de outras religiões, ainda minoritárias.

Uma possível explicação para o sentido negativo do impacto das afiliações religiosas em contraposição aos "sem religião" pode ser buscada na teoria do desenvolvimento humano e segurança existencial de Ronaldo Inglehart e seus colaboradores (2002; 2009). De acordo com essa teoria, o desenvolvimento econômico e a modernização geram mudanças culturais e sociais, acarretando a emergência de valores de autoexpressão, na busca pela autonomia individual e pela emancipação. Tais valores seriam acompanhados por uma substituição de prioridades e de normas, dentre elas religiosas, e do surgimento de demandas por escolhas mais livres em todas as dimensões da vida (INGLEHART e WELZEL, 2009).

Com este processo, os indivíduos que se tornariam mais críticos em relação as instituições tradicionais, tenderiam a rejeitar cada vez mais a autoridade externa conforme os valores de autoexpressão fossem sendo incorporados e a autonomia individual fosse ganhando maior ênfase. Segundo os autores, esse desenvolvimento humano teria influência tanto na religiosidade dos indivíduos quanto no seu comportamento político. Essa mudança nas prioridades individuais possibilitaria o surgimento de novas demandas de participação e uma cidadania mais crítica, que colocaria em questionamento não apenas as instituições religiosas como também as instituições políticas tradicionais, contribuindo para o aumento da participação em atividades mais contestatórias ou de protesto (IBIDEM). 
Tais argumentos explicariam a relação entre ser "sem religião" e participar em protestos, uma vez que indivíduos mais autônomos se afastariam de instituições mais burocratizadas, como a igreja, e se aproximariam de formas de participação políticas mais diretas. Mas como explicar os efeitos negativos das afiliações religiosas sobre a participação em manifestações e protestos públicos em contraposição ao efeito positivo do ativismo religioso, se Verba, Schlozman e Brandy (1995) apontam a importância das diferenças denominacionais e da assiduidade?

Para entender tal paradoxo é necessário termos em mente que optamos por inserir no modelo o ativismo e a denominação simultaneamente, fazendo com que os efeitos fossem mutualmente controlados. Ou seja, as denominações diminuem a chance de ativismo de protesto, mas entre os membros de uma mesma afiliação religiosa a assiduidade tem efeito positivo. Logo, se tomarmos dois católicos, um ativo tem mais chance de envolvimento em protesto do que o inativo. Isso vale para todas as demais denominações. Assim, enquanto tivemos um valor positivo no que se refere ao papel do ativismo religioso na participação em protesto, o mesmo não ocorre com as denominações, que além de diminuírem as probabilidades de engajamento político em comparação aos "sem religião", ainda não diferem significativamente entre si. Esses resultados, assim como os encontrados por Jones-Correa e Leal (2001), Lockerbie (2013) e Gerber, Gruber e Hungerman (2015), nos fazem pensar que a frequência à cultos e missas é mais importante para a ação política direta do que a denominação da qual o indivíduo faz parte.

Dedicando alguma atenção aos controles, observamos que, no que diz respeito as variáveis ligadas à teoria das queixas, apenas a satisfação com a democracia deixou de apresentar efeito significativo sobre a medida dependente. A satisfação com a vida e a confiança institucional impactam negativamente a chance de protestar, a primeira em $12 \%$ e a segunda em $50 \%$. Tais resultados nos afastam das conclusões de Dalton, Van Sickle e Weldon (2009), para os quais os efeitos das queixas parecem não ter relação com as atividades de protesto, não confirmando a relação explicativa entre o sentimento de privação e o comportamento político. Todavia, nos aproximam dos achados de Ribeiro e Borba (2015), que atestando a relevância da satisfação com a vida, confirmaram o papel do descontentamento/insatisfação individual na atividade política direta na América Latina.

A variável sobre valores ideológicos segue caminho semelhante, apresentando, contudo, um efeito negativo pequeno de $5 \%$. Como a medida é codificada em uma escala partindo da esquerda, o resultado indica que quanto mais identificado com a direita menor a probabilidade de protesto. Mais uma vez nossos achados caminham no sentido da literatura politológica já estabelecida, segundo a 
qual o envolvimento em modalidades contestatórias seria mais comum entre os indivíduos auto posicionados à esquerda (DALTON e VAN SICKLE, 2005; DALTON, VAN SICKLE e WELDON, 2009; RIBEIRO e BORBA, 2015).

Foram entre as variáveis de controle ligadas à teoria dos recursos que encontramos efeitos positivos, confirmando os achados de Verba, Schlozman e Brady (1995). Em nosso modelo, a escolaridade incrementa em $62 \%$ a participação em protestos. Tal achado não é uma surpresa, uma vez que diferentes autores já destacaram os múltiplos papéis da educação na participação. O mesmo ocorreria com o envolvimento em atividades voluntárias, medida aqui pela participação em associação de bairro ou juntas de melhorias para a comunidade, que no modelo aumenta em $51 \%$ a probabilidade de um indivíduo agir politicamente. Tais atividades, além de permitirem o desenvolvimento de habilidades cívicas ainda abririam as portas para o processo de recrutamento e mobilização (VERBA, SCHLOZMAN e BRADY, 1995).

Por fim, encontramos que altos níveis de interesse por política estão associados ao protesto, aumentando em $60 \%$ a probabilidade de participação. Esses resultados demonstram que, assim como foi apontado por Verba, Schlozman e Brady (1995), cidadãos que são mais interessados em política, que a acompanham, que se importam com o que acontece e se preocupam, são mais ativos politicamente. Desta forma, nossos resultados nos permitem afirmar que o envolvimento em protesto está relacionado com os recursos intelectuais e com a participação em atividades de adesão voluntária, achados que estão em consonância com os resultados apresentados por Ribeiro e Borba (2015) e reafirmam a pertinência da teoria do Voluntarismo Cívico para a América Latina.

Como já apontamos acima, a última coluna da Tabela 2 apresenta a variância dos efeitos de todos esses preditores de nível individual em um modelo com efeitos aleatórios. Indo diretamente para as variáveis que nos interessam nesse trabalho, constatamos que a variabilidade dos impactos das denominações é mais expressiva (católico 0,096, evangélico 0,088 e outras religiões 0,025) do que as verificadas para o ativismo religioso $(0,005)$. As variâncias, apesar de modestas, indicam que os efeitos da religião sobre o comportamento de protesto têm magnitudes distintas entre os países. Dentre as variáveis de controles, notamos que, apesar de quase todas mostrarem alguma variância, a mais significativa foi a confiança institucional, com 0,329 .

Para testar a hipótese do efeito contextual, ligado ao maior ou menor grau de abertura do mercado religioso, inserimos as variáveis de nível macro em um modelo completo, cujos resultados são dispostos na Tabela 3. Inicialmente destacamos que essas inserções produziram pouco impacto 
nas medidas individuais, mantendo a significância e o sentido dos efeitos naqueles que já apareciam como preditores relevantes no primeiro modelo.

TABELA 3 - EFEITOS DE PREDITORES INDIVIDUAIS E NACIONAIS SOBRE PARTICIPAÇÃO EM PROTESTOS NA AMÉRICA LATINA

\begin{tabular}{|c|c|c|}
\hline & $\begin{array}{c}\text { B } \\
\text { (erro) }\end{array}$ & $\operatorname{Expo}(B)$ \\
\hline Católico & $\begin{array}{c}-0,50 * * * \\
(0,061)\end{array}$ & 0,60 \\
\hline Evangélico & $\begin{array}{c}-0,48 * * * \\
(0,072)\end{array}$ & 0,61 \\
\hline Outras Religiões & $\begin{array}{c}-0,50 * * * \\
(0,097)\end{array}$ & 0,60 \\
\hline Ativismo Religioso & $\begin{array}{c}0,09 * \\
(0,041)\end{array}$ & 1,09 \\
\hline Associação & $\begin{array}{c}0,41 * * * \\
(0,018)\end{array}$ & 1,51 \\
\hline Escolaridade & $\begin{array}{c}0,48 * * * \\
(0,040)\end{array}$ & 1,61 \\
\hline Interesse & $\begin{array}{c}0,47 * * * \\
(0,018)\end{array}$ & 1,60 \\
\hline Satisfação Democracia & $\begin{array}{c}-0,01 \\
(0,026)\end{array}$ & 0,98 \\
\hline Satisfação Vida & $\begin{array}{c}-0,11 * * * \\
(0,023)\end{array}$ & 0,88 \\
\hline Confiança & $\begin{array}{c}-0,68 * * * \\
(0,085) \\
\end{array}$ & 0,50 \\
\hline Ideologia & $\begin{array}{c}-0,04 * * * \\
(0,006)\end{array}$ & 0,95 \\
\hline Suporte Oficial & $\begin{array}{c}0,04 \\
(0,050)\end{array}$ & 1,04 \\
\hline Educação Religiosa & $\begin{array}{c}0,02 \\
(0,084)\end{array}$ & 1,02 \\
\hline Restrição do Governo & $\begin{array}{c}-0,02 \\
(0,040)\end{array}$ & 0,97 \\
\hline Hostilidade Social & $\begin{array}{c}0,07 . \\
(0,044)\end{array}$ & 1,07 \\
\hline V-Dem & $\begin{array}{c}0,02 \\
(0,051)\end{array}$ & 1,02 \\
\hline Desemprego & $\begin{array}{c}0,01 \\
(0,042)\end{array}$ & 1,60 \\
\hline AIC & 21660,4 & \\
\hline Variância & 0,1902 & \\
\hline
\end{tabular}

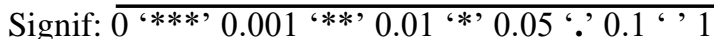

FONTE: Elaboração própria com base nos dados do Lapop 2012, 2016/17, Pew e Arda 
O Suporte Oficial a Religião, considerado aqui medida adequada da regulamentação estatal nesse mercado, apesar de apresentar coeficiente positivo de 0,04 não alcançou nível de significância estatístico aceitável. A hipótese de que a percepção sobre a forma como o Estado trata as denominações (de maneira prejudicial, neutra ou favorável) influencia a probabilidade de envolvimento em protestos no nível individual não apresenta sustentação empírica na região analisada. O mesmo ocorreu com a obrigatoriedade da educação nas escolas públicas, variável apresentada por Kuru (2009) e por Fox (2015) como de grande importância nas discussões e conflitos históricos e contemporâneos sobre a relação entre religião e Estado. Não foi diferente no caso da medida de Restrição de Governo, também sem efeito estatisticamente significativo.

Deslocando a atenção para restrições originadas da sociedade civil, mensuradas pelo Índice de Hostilidade Social (SHI), encontramos quadro distinto, já que essa medida se mostrou relevante, aumentando em $7 \%$ as chances de participação em atividade de protesto no bloco de países latinoamericanos.

Diferentemente do que a literatura sobre a América Latina tem apontado, restrições estatais não têm gerado reação individual na forma de protesto político, todavia, o contexto social desfavorável parece atuar nesse sentido. Mais importante do que a percepção de atuação tendenciosa das instituições formais, parece ser a percepção de que a sociedade se opõe a denominações religiosas minoritárias. Essa conclusão, todavia, necessita ser corroborada pela observação dos efeitos dessa medida de hostilidade social sobre indivíduos de distintas religiões. Ao interagirmos esse índice nacional com as diferentes denominações podemos testar se são os membros de religiões minoritárias que têm a sua probabilidade de envolvimento político elevada. Adicionalmente, interagimos também essa medida nacional com o ativismo religioso individual, independente do credo dos entrevistados.

Os resultados dessa interação cross-level (Tabela 4) indicam que as variáveis individuais não têm seu efeito alterado em contextos de maior ou menor hostilidade. Desta forma, os efeitos do status de praticante religioso e do pertencimento a determinada denominação sobre a ação política direta não parecem ser intermediados, ou moderados, pelo maior ou menor nível de hostilidade social dos países, sugerindo que a existência de hostilidades religiosas no contexto nacional afetam de maneira semelhante as diferentes religiões, e não de forma especial aquelas que eventualmente ocupam posição minoritária no mercado. 
TABELA 4 - INTERAÇÃO ENTRE OS CONDICIONANTES INDIVIDUAIS RELIGIOSOS E NACIONAIS SOBRE A PARTICIPAÇÃO EM PROTESTOS NA AMÉRICA LATINA

\begin{tabular}{|c|c|c|}
\hline & $\begin{array}{c}\text { B } \\
(\text { erro) }\end{array}$ & $\operatorname{Expo}(B)$ \\
\hline Católico*Hostilidade & $\begin{array}{c}-0,01 \\
(0,023)\end{array}$ & 0,98 \\
\hline Evangélico*Hostilidade & $\begin{array}{c}-0,00 \\
(0,028)\end{array}$ & 0,99 \\
\hline Outras Religiões*Hostilidade & $\begin{array}{c}-0,01 \\
(0,037)\end{array}$ & 0,98 \\
\hline Ativismo*Hostilidade & $\begin{array}{c}-0,01 \\
(0,015)\end{array}$ & 0,98 \\
\hline
\end{tabular}

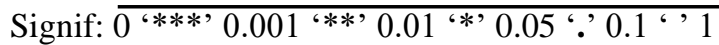

FONTE: Elaboração própria com base nos dados do Lapop, 2012, 2016/17, Pew e Arda

O mesmo ocorre no caso do ativismo religioso, que não tem o seu efeito alterado por essa medida contextual. Ou seja, indivíduos que mais assiduamente frequentam as atividades religiosas, independentemente da denominação, tendem a ser mais propensos ao ativismo político não importando o contexto social mais ou menos hostil.

Para finalizar, dedicamos alguma atenção aos controles de nível nacional adicionados ao modelo (Tabela 3). No que se refere aos efeitos da dimensão do desenvolvimento político nossos dados não nos permitem inferir o papel das estruturas institucionais e dos sistemas políticos na atividade de protesto, pois, apesar do indicador do V-Dem apresentar um sentido positivo, este não se mostrou estatisticamente significativo. Tais resultados se distanciam, por um lado, dos encontrados por Dalton, Van Sickle e Weldon (2009) e, por outro, dos registrados por Ribeiro e Borba (2015). Os primeiros, utilizando como medida o indicador Rule of Law, demonstram que as ações de protesto são ampliadas em contextos institucionais politicamente abertos. Já Ribeiro e Borba encontraram resultados opostos, isto é, sistemas mais fechados tenderiam a ampliar o engajamento individual em modalidades de contestação, reafirmando o efeito positivo das estruturas fechadas sobre o protesto. Ao contrário do que esperávamos, nossos resultados diferem de ambas as pesquisas e possíveis explicações para tais discrepâncias poderiam ser as seguintes. Primeiro, Dalton, Van Sickle e Weldon (2009) utilizam uma base de dados ampla, cuja amostra abrange setenta e oito nações, entre as quais encontram-se países com diferentes níveis de desenvolvimento político. Ribeiro e Borba (2009) focalizam a América Latina, contudo, utilizam dados de ano anterior (2005) e um maior número de modalidades contestatórias. Além disso, utilizam como medida de abertura política o indicador de Liberdade produzido pela Freedom 
House. Independente dos motivos, contudo, essas divergências são de difícil resolução, já que são empregadas medidas distintas para materiais empíricos diferentes. Novas pesquisas precisam ser conduzidas para validar essas posições.

O mesmo ocorreu para a variável de desenvolvimento econômico, isto é, apesar de seu sentido positivo, o resultado não se mostrou estatisticamente significativo sobre a medida de protesto. O quadro por nós encontrado, mais uma vez, aponta para caminhos diferentes dos encontrados por Dalton, Van Sickle e Weldon (2009), que identificaram maior tendência ao protesto em cidadãos de nações mais afluentes. O fato desses autores utilizarem dados de países tanto desenvolvidos quanto em desenvolvimento pode explicar essa diferença, já que ao reduzirmos nosso alcance apenas para nações em desenvolvimento esse efeito do contexto econômico tenderia a se enfraquecer.

Nossos resultados, então, não permitem qualquer afirmação sobre efeitos significativos da situação política e econômica, tão discutidos pelas teorias das Estruturas de Oportunidade Política e dos Recursos. Em contextos relativamente semelhantes e marcados por forte desigualdade social o predomínio das variáveis individuais, principalmente ligadas aos recursos, se impõe.

\section{CONSIDERAÇÕES FINAIS}

Nosso objetivo com o presente artigo foi contribuir com a discussão sobre a relação entre religião e o comportamento político na América Latina, por meio do estudo dos efeitos da religião individual (denominação e ativismo) e do contexto religioso nacional sobre o engajamento em manifestações e protestos públicos. Nosso intuito foi ampliar a agenda de pesquisa já existente, abordando não a elite política e religiosa, mas sim os indivíduos, o cidadão médio, e outros segmentos denominacionais para além do evangélico, destacando também os católicos e àqueles que se proclamam "sem religião".

Nossa hipótese central era que entre os países latino-americanos a maior ou menor abertura do mercado religioso à grupos minoritários não afeta a probabilidade de ativismo político do cidadão médio. Trabalhamos também com as hipóteses complementares de que o ativismo religioso, medido pela frequência à cultos/missas, teria um efeito positivo sobre o envolvimento em ações de protesto enquanto a filiação religiosa específica dos entrevistados não afetaria a sua probabilidade de atuação. 
Os resultados indicam efeitos reduzidos e oscilantes da afiliação religiosa e impactos mais consistentes da frequência aos cultos/missas, independentes do componente denominacional minoritário ou majoritário. Enquanto a frequência às instituições religiosas mostrou possuir um efeito positivo na ação política direta na América Latina, a afiliação religiosa seguiu caminho contrário, diminuindo as probabilidades de um religioso, em comparação a um indivíduo sem religião, engajar-se nesse tipo de modalidade política.

Os efeitos do contexto religioso reforçam essa conclusão, já que a maioria dos indicadores não se mostrou relevante na explicação da participação em protesto, sem afetar também o modo como os condicionantes individuais operam. Diferentemente do que a literatura sobre a América Latina tem apontado, restrições estatais não têm gerado reação no nível individual na forma de protesto político. Os dados indicaram que apesar do Índice de Hostilidade Social se mostrar significativo, nem mesmo quando colocamos preditores individuais aceitos pela literatura politológica, como a assiduidade e a afiliação religiosa, tal contexto se mostra relevante na explicação dos efeitos da participação. Isso sugere que a existência de hostilidades religiosas no contexto nacional afeta de maneira semelhante as diferentes religiões, e não de forma especial aquelas que eventualmente ocupam posição minoritária no mercado.

\section{REFERÊNCIAS}

BASTIAN, Jean-Pierre. Los Nuevos Partidos Políticos Confesionales Evangélicos y su Relación con el Estado en América Latina. Estudos Sociológicos, XVII, 49, p.153-173, 1999.

BOAS, Taylor C. Expanding the Public Square: Evangelicals and Electoral Politics in Latin America", in: D. KAPISZEWSKI, S. LEVITSKY, D. YASHAR (edit), The Inclusionary Turn in Contemporary Latin America. New York: Cambridge University Press, 2018.

CAMPBELL, David E. Acts of Faith: Churches and Political Engagement. Political Behavior, 26, 2, p.155-180, 2004.

DALTON, Russel; VAN SICKLE, Alix. The Resource, Structural, and Cultural Bases of Protest. UC Irvine: Center for Study of Democracy, 2005.

DALTON, Russel; VAN SICKLE, Alix; WELDON, Steven. The Individual-Institutional Nexus of Protest Behaviour. Brithish Journal of Political Science, 40, p. 51-73, 2009.

DJUPE, Paul; GRANT, Tobin. Religious Institutions and Political Participation in America. Journal of Scientific Study of Religion, 40, 2, p. 302-314, 2001. 
EISINGER, Peter. The Conditions of Protest Behavior in American Cities. The American Political Science Review, 67, 1, p. 11-28, 1973.

FOX, Jonathan. Political Secularism, Religion, and the State. New York: Cambridge University Press, 2015.

GERBER, Alan; GRUBER, Jonathan; HUNGERMEN, Daniel. Does Church Attendance Cause People to Vote? Using Blue Laws' Repeal to Estimate the Effect of Religiosity on Voter Turnout. British Journal of Political Science, 46, 3, p. 481-500, 2015.

GURR, Ted Robert. Why Men Rebel. Princeton: Princeton University Press, 1971.

HELMSDORFF, Daniela. Participación política evangélica en Colombia (1990-1994). Historia Critica, 12, p. 77-86, 1996.

HOSMER, David; LEMESHOW, Stanley; STURDIVANT, Rodney. Applied logistic regression. NY: Wiley \& Sons, 2013.

HOX, Joop. Multilevel analysis: techniques and applications. 2a edição, New York, Routledge, 2010 .

INGLEHART, Ronald; CATTERBERG, Gabriela. Trends in Political Action: The Developmental Trend and the Pos-Honeymoon Decline. International Journal of Comparative Sociology, 43, 35, p. 300-316, 2002.

INGLEHART, Ronald; WELZEL, Christian. Modernização, Mudança Cultural e Democracia: A Sequência do Desenvolvimento Humano. São Paulo: Francis, 2009.

JONES-CORREA, Michael; LEAL, David. Political Participation: Does Religion Matter? Political Research Quarterly, 4, p.751-770, 2001.

KITSCHELT, Herbert P. Political Opportunity Structures and Political Protests: Antinuclear Movements in Four Democracies. British Journal of Political Science, 16, 1, p. 57-85, 1986.

KURU, Ahmet T. Secularism and State Policies toward Religion: The United States, France, and Turkey. New York: Cambridge University Press, 2009.

LOCKERBIE, Brad. Race and Religion: Voting Behavior and Political Attitudes. Social Science Quarterly, 94, 4, p.1145-1158, 2013.

MAROSTICA, Matt. La Nueva Política Evangélica: El Movimiento Evangélico y el Complot Católico en la Argentina. Ciencias Sociales y Religión/Ciências Sociais e Religião, 2, 2, p.11-30, 2000.

MCADAM, Doug; MCCARTHY, John; ZALD, Mayer. Movimientos Sociales: Perspectivas Comparadas: Oportunidades Políticas, Estructuras de Movilización y Marcos Interpretativos Culturales. Madrid: Istmo, 1999. 
MOSELEY, Mason Wallace. Contentious Engagement: Understanding Protest Participation in Latin American Democracies. Journal of Politics in Latin America, 7, 3, p.3-48, 2015.

PUTNAM, Robert. Bowling Alone: The Collapse and Revival of American Community. New York: Simon \& Schuster, 2000.

RAUDENBUSH, Stephen W; BRYK, Anthony S. Hierarchical Linear Models. Chicago: University of Chicago, 2002.

RIBEIRO, Ednaldo Aparecido; BORBA, Julian. Participação Política na América Latina. Maringá: Eduem, 2015.

SCHLOZMAN, Kay Lehman; VERBA, Sidney; BRADY, Henry E. The Unheavenly Chorus: Unequal Political Voice and the Broken Promise of American Democracy. Princeton: Princeton University Press, 2012.

SMITH, Amy Erica. Mobilizing the People of God: How Religion is Changing Brazilian Democracy. Submetido à publicação, versão de 2018.

SOMMET, Nicholas; MORSELLI, Davide. Keep Calm and Learn Multilevel Logistic Modeling: A Simplified Three-Step Procedure Using Stata, R, Mplus, and SPSS. International Review of Social Psychology, 30, 1, p.203-218, 2017.

TARROW, Sidey. El Poder em Movimiento: Los Movimientos Sociales, la Acción Colectiva y la Política. Madrid: Alianza Editorial, 1997.

VERBA, Sidney; SCHLOZMAN, Kay Lehman; BRADY, Henry E. Voice and Equality: Civic Volunteerism in American Politics. Cambridge, MA: Harvard University Press, 1995.

WYNARCZYK, Hilario. Los Evangélicos y la Política en la Argentina. Boletin de Lecturas Sociales y Economicas, 31, p.52-66, 2007.

\section{ANEXO}

\section{Suporte Oficial do Estado: categoria de 0 a 13}

0 = Hostilidade Específica: A hostilidade e a perseguição aberta à religião onde a ideologia estatal especificamente destaca a religião em geral ou a religião é de alguma outra forma singularmente apontada para a perseguição (ex. a exURSS)

1 = Religião Controlada pelo Estado, Atitude Negativa: O Estado controla todas as instituições religiosas e desencoraja a expressão religiosa fora dessas instituições. Isso faz parte da política do Estado de manter o controle social ou manter a religião sob controle, e não devido ao apoio ideológico à religião.

2 = Hostilidade Não Específica: Embora o Estado seja hostil à religião, essa hostilidade está mais ou menos no mesmo nível que a hostilidade do Estado a outros tipos de organizações não estatais. A religião não é destacada.

3 = Separacionista: A separação oficial entre Igreja e Estado e o Estado é um pouco hostil à religião. Isso inclui esforços para remover a expressão da religião por cidadãos privados da esfera pública.

4 = Acomodação: A separação oficial de Igreja e Estado e o Estado tem uma atitude benevolente ou neutra em relação à religião em geral.

5 = Suporte: o Estado apóia todas as religiões de maneira mais ou menos igualitária. 
6 = Cooperação: O Estado fica aquém de endossar uma determinada religião, mas certas religiões se beneficiam mais do apoio do Estado do que outras. (Esse suporte pode ser monetário ou legal)

7 = Preferências Multi-Diferenciadas 2: duas ou mais religiões são claramente preferidas pelo Estado, recebendo o maior número de benefícios, existe um ou mais níveis de religiões que recebem menos benefícios do que as religiões preferidas, mas mais do que algumas outras religiões.

8 = Preferências Multi-Diferenciadas 1: uma religião é claramente preferida pelo Estado, recebendo o maior número de benefícios, existe um ou mais níveis de religiões que recebem menos benefícios do que a religião preferida, mas mais do que algumas outras religiões.

9 = Religião Preferida: Embora o Estado não endosse oficialmente uma religião, uma religião serve extraoficialmente como a religião do estado recebendo reconhecimento ou benefícios exclusivos. Todas as religiões minoritárias recebem tratamento similar entre si.

10 = Religião Estatal Ativa: O Estado apóia ativamente a religião, mas a religião não é obrigatória e o Estado não domina as instituições oficiais da religião.

11 = Religião Controlada pelo Estado, Atitude Positiva: O estado apoia uma religião e controla substancialmente suas instituições, mas tem uma atitude positiva em relação a essa religião.

12 = Estado Religioso 2: Religião obrigatória para membros da religião oficial.

13 = Estado Religioso 1: Religião obrigatória para todos.

Educação Requerida: categoria de 0 a 4

0 = Não obrigatória.

1 = Opcional ou há uma escolha entre religião e um curso não religioso sobre tópicos como ética, filosofia ou religiões do mundo.

2 = Obrigatória, mas, mediante solicitação específica, o aluno pode optar por sair do curso. (isso é diferente da categoria acima em que, no caso acima, a escolha é automática e, nesse caso, uma solicitação especial para desativação deve ser feita.)

3 = Obrigatória para alguns que não têm a capacidade de optar, o curso deve ser em religião, mas opcional para outros, ou existe para alguns a opção de fazer um curso não religioso sobre tópicos como ética, filosofia ou religiões do mundo. 4 = Obrigatória para todos, o curso deve ser em religião.

Índice de Restrição de Governo (GRI): objetivo é medir não apenas as leis, como também as políticas e ações governamentais que restringem crenças ou práticas religiosas. Tal índice compreende 20 medidas sobre restrições, banimentos, proibições, limitações e favorecimentos - o teste de confiança estatística do índice apresentou um coeficiente de 0.91 , mostrando-se estatisticamente apropriado - em uma métrica de 0 a 10 pontos, sendo zero o nível mais baixo de restrições e 10 o mais alto. As questões são codificadas em uma escala padrão de zero a um ponto e o valor total do índice foi ajustado de forma que tenha um valor máximo de 10 e um intervalo possível de zero a 10 , dividindo a soma das variáveis por dois.

Índice de Hostilidades Sociais (SHI): cuja função é medir os atos de hostilidade religiosa praticados por particulares, organizações ou grupos da sociedade. Assim como o anterior, este índice é construído em uma métrica de 0 a 10 pontos, com zero indicando impedimentos muito baixos às crenças e práticas religiosas e 10 indicando impedimentos muito altos. Os indicadores foram somados e definidos para ter um intervalo possível de zero a 10, dividindo a soma das variáveis por 1,3. Esse índice compreende 13 medidas de hostilidade - que submetidas ao teste de confiabilidade estatística apresentou um coeficiente de 0.89 -, dentre elas conflitos armados relacionados à religião, violência popular, assédio ou outras intimidações ou abusos relacionados à religião

V-Dem: Tal índice é desenvolvido com base na definição de Dahl de poliarquia e conta com indicadores de liberdade de associação, eleições limpas, liberdade de expressão, se o chefe do executivo é escolhido em eleições livres e a extensão dos direitos eleitorais. Esta medida, bem como os demais indicadores sóciopolíticos foram padronizados em uma escala de 10 pontos. O índice é agregado usando essa fórmula: v2x_polyarchy= .5 MPI +0.5 API $=$ $.5\left(\mathrm{v} 2 \mathrm{x} \_\right.$elecoff $* \mathrm{v} 2 \mathrm{xel}$ _frefair $* \mathrm{v} 2 \mathrm{x} \_$frassoc_thick $* \mathrm{v} 2 \mathrm{x} \_\mathrm{suffr} * \mathrm{v} 2 \mathrm{x} \_$freexp_thick $)+.5\left(1 / 8 \mathrm{v} 2 \mathrm{x} \_\right.$elecoff $+1 / 4$ $\mathrm{v} 2 \mathrm{xel} \_$frefair $+1 / 4 \mathrm{v} 2 \mathrm{x} \_$frassoc_thick $+1 / 8 \mathrm{v} 2 \mathrm{x} \_$suffr $+1 / 4 v 2 x \_$freexp_thick) . Para mais informações acessar: https://www.vdem.net/en/.

Taxa de Desemprego: Dados fornecidos pelo Banco Mundial e disponíveis em: https://data.worldbank.org/indicator/SL.UEM.TOTL.ZS 
Participação em Manifestações ou Protestos Políticos: [prot] Nos últimos doze meses, o(a) sr./sra., participou de alguma manifestação ou protesto público? 0 = Não Participa; 1 = Participa

Ativismo Religioso: [atvrel] “Com que frequência o(a) sr./sra. vai à missa ou culto religioso?” 0 = Não Ativo; $1=$ Ativo

Afiliação Religiosa: [denr.evan] "Qual a sua religião, se tiver?” 0 = Católico; 1 = Evangélicos; 2 = Sem Religião; 3 = Outros

Satisfação com a Vida: [svida.n] Para começar, em geral, até que ponto o(a) sr./sra. está satisfeito(a) com sua vida? O(A) sr./sra. diria que está. 0 = Muito Insatisfeito(a); 1 = Pouco Insatisfeito(a); 2 = Pouco Satisfeito(a); $3=$ Muito Satisfeito(a)

Satisfação com a Democracia: [sdem.n] De uma maneira geral, o(a) sr./sra. está muito satisfeito(a), satisfeito(a), insatisfeito(a) ou muito insatisfeito(a) com o funcionamento da democracia? 0 = Muito Insatisfeito(a); 1 = Insatisfeito(a); 2 = Satisfeito(a); 3 = Muito Satisfeito(a)

Interesse por Política: [intpol.n] O quanto o(a) sr./sra. se interessa por política: muito, algo, pouco ou nada? $0=$ Nada; $1=$ Pouco; 2 = Algo; 3 = Muito

Participação em Associações de Bairro ou Juntas de Melhoria para a Comunidade: [assb.n] Reuniões de uma associação de bairro ou junta de melhorias para a comunidade? Assiste... 0 = Nunca; 1 = Uma ou duas vezes ao ano; 2 = Uma ou duas vezes ao mês; 3 = Uma vez por semana

Situação Econômica do País: [soct2] O(A) sr./sra. considera que a situação econômica atual do país está melhor, igual, ou pior que há doze meses? 0 = Pior; 1 = Igual; 2 = Melhor

Situação Econômica Individual: [idio2] O(A) sr./sra. acha que sua atual situação econômica está melhor, igual ou pior que a de há doze meses? 0 = Pior ; 1 = Igual: 2 = Melhor 